\title{
KEVÄTVEHNÄLAJIKKEIDEN TUNTOMERKEISTÄ
}

\author{
Elli Korpinen \\ Valtion siementarkastuslaitos, Helsinki
}

Saapunut 14. 1. 1956

Viljojen kylvösiemenkaupassa meillä nykyään jo varsin yleisesti myyjä antaa ostajalle vakuuden myymänsä lajikkeen aitoudesta. Korkeampien laatuluokkien, valio- ja laatusiemenen siemeneristä, se onkin pakollista, mutta tavallista kauppasiementä meillä sen sijaan saa myydä vaikkapa vain pelkällä lajinimellä varustettuna. Tavallisen kauppasiemenenkin aitoutta on Valtion siementarkastuslaitoksessa kuitenkin pyritty valvomaan ainakin siinä määrin, että pahimmat virheet lajikkeiden nimissä tulisivat korjatuiksi silloinkin, kun siemennäytteen tarkastuttaja ei ole erikoisesti aitousmääritystä pyytänyt. Tällainen työ edellyttää kuitenkin, että tarkastuslaitoksessa tunnetaan lajikkeet. Siihen päämäärään on siementarkastuslaitoksessa pyrittykin alusta saakka. Mutta lajikkeet vaihtuvat uusiin lajikkeisiin siemenkaupassa usein niin nopeasti, että tuskin on uuden lajikkeen tuntomerkkeihin ehditty tutustua, kun lajike jo jää kaupasta pois ja korvataan uudella. Kaupasta poistettu lajike saattaa silti jäädä viljelyyn ja tulla taas jonkin ajan kuluttua uudelleen siemenmarkkinoille ellei juuri sellaisena niin mahdollisesti muihin lajikkeisiin sekoittuneena. Siementarkastajan pitää sen vuoksi tuntea sekä parhaillaan kaupassa olevat että kaupasta jo yleensä syrjäytyneet, mutta vielä osittain viljelyyn jääneet lajikkeet.

Sen vuoksi seuraavaan tutkimiskaavaan, jossa selostetaan niitä k e vä tvehnien tuntomerkkejä, joiden nojalla kevätvehnälajikkeet Valtion siementarkastuslaitoksessa määritetään, on otettu paljon sellaisiakin lajikkeita, joilla ei tällä hetkellä ole siemenkaupassa mitään merkitystä. Siinä ovat kaikki ne kevätvehnälajikkeet, joista on siementarkastuslaitokseen saapunut näytteitä viimeksi kuluneiden 20 vuoden aikana. Selostettavia lajikkeita on kaikkiaan 25.

Tässä aikakauslehdessä on aikaisemmin (Maatal.tiet. aikak. 13 (1941): 145164) esitetty kevätvehnien tutkimiskaava, jonka täydennykseksi seuraava kaava on laadittu. Niissä molemmissa on lajikkeet ryhmitelty ensin joko koko kasveissa tai siemenissä selvimmin havaittavien tuntomerkkien — kuten vihneiden pituu- 
den, kaleiden värin jne. - mukaan ja sen jälkeen on kunkin lajikkeen kohdalla selostettu tarkemmin ko. lajikkeen erikoistuntomerkkejä.

Selostus perustuu valtion siementarkastuslaitoksen laboratoriossa ja koekentällä suoritettuihin tutkimuksiin. Kun eri lajikkeet ovat joutuneet tutkittaviksi yleensä sitä mukaa kuin ne ovat ilmaantuneet kauppaan ja saapuneet tarkastettaviksi, eivät kaikki selostettavat lajikkeet ole olleet yhtä monta vuotta tutkittavina; jotkut vanhimmat ja uusimmat lajikkeet ovat olleet tarkastettavina vain parikin vuotta, joten niistä esitetyt tiedot eivät ole yhtä luotettavia kuin yleisimmistä lajikkeista esitetyt tiedot, jotka suurelta osalta perustuvat lähes 20 vuoden aikana suoritettuihin tutkimuksiin.

Niihin kasvien morfologisiin ominaisuuksiin, joihin lajikemäärityksissä huomio kiinnitetään, voivat lajikkeesta riippumattomat tekijät, kuten erilaiset viljelyolot, aiheuttaa sen verran vaihteluita, että sellaisetkin lajikkeet, jotka yleensä voidaan helposti erottaa jo pelkistä siemenistäkin, voivat joskus olla vaikeasti erotettavissa.

Kun lajikkeiden määrityksessä kentällä, jossa on kasvamassa paljon lajikkeita vierekkäin, on a i ka is u u s havainnoista paljon apua, luetellaan seuraavassa kevätvehnälajikkeet siinä järjestyksessä kuin ne keskimäärin eri vuosina ovat a l k a n e e t t äh ki ä siementarkastuslaitoksen koekentällä Viikissä. Tässä tarkoituksessa voi tietenkin käyttää yhtä hyvin lopullista valmistumispäivää, mutta tuleentumisaste on vaikeampi määrittää täsmällisesti kuin tähkimisen alkaminen. Eri lajikkeiden lopullinen tuleentumisjärjestys ei ole aivan sama kuin tähkälletulojärjestys.

Tähkälletulojärjestys:

1. Tammi, Apu, Pika I ja II, Garnet

2. Sopu, Kimmo

3. Hopea, Terä

4. Kiuru

5. Timantti I, Aurore

6. Fylgia, Marquis, "Vihnevehnä» (sveitsil.)

7. Hankkijan Ruskea

8. Timantti II, Touko

9. Svenno, "Kanadalainen"

10. Kärni, Drott, Brons

11. Pondus

12. Extra Kolben II.

Eri lajikkeiden tähkälletulojärjestys on vuodesta toiseen pysynyt suurin piirtein samana, mutta eri lajikkeiden tähkälletulon välinen aika on sen sijaan vaihdellut hyvinkin paljon. Joinakin vuosina on esimerkiksi aikaisimman ja myöhäisimmän ryhmän välillä ollut tähkimisen alkamisessa vain 6 päivän, mutta joskus taas jopa 15 päivänkin ero. 
KEVÄTVEHNIEN TUTKIMISKAAVA

\section{VIHNEET LYHYET}

\section{a) Kaleet ruskeat, kaljut}

b) Lehden korvakkeiden reunoissa on karvoja; korvakkeet melko suuret. Jyvät värittyvät fenolikäsittelyssä ${ }^{1}$ ) vaalean ruskeiksi.

c) Tähkälapakon alimpien nivelten reunassa p i t k ä ä nukkaa. Korren ylin solmu melkein kalju. Tähkä pitkä, kapeahko, kärjestä suippeneva. Kaleet kapeat. Jyvä pitkulainen, litteä, sileä.

cc) Tähkälapakon alimmat nivelet $\mathrm{k} \mathrm{a} \mathrm{j} \mathrm{u} \mathrm{t}$ tai on reunassa $1 \mathrm{y} \mathrm{h}$ y $\mathrm{t} t$ ä nukkaa.

Muistuttaa Timantti I:tä, mutta eroaa siitä seuraavasti: Lehdet varsinkin ennen tähkimistä yleensä nuokkuvammat; korsi tähkimisestä lähtien vähän lyhyempi $(15-20 \mathrm{~cm})$; korren solmussa nukkaa vähän enemmän; tähkä vähän leveämpi ja vähemmän suippeneva sekä vielä tuleentuneenakin pystympi; jyvä yleensä pienempi, suhteellisesti lyhyempi ja paksumpi kuin Timantti I:1lä

Melkein kuten Timantti II, mutta korren ylimmässä solmussa (DIAMANT II) ja korressa solmun yläpuolella yleensä runsaasti nukkaa. Heteen

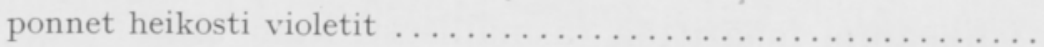

bb) Lehden korvakkeiden reunoissa e i karvoja. Korvakkeet pienet. Korren ylimmässä solmussa ja korressa solmun yläpuolella runsaasti nukkaa. Heteen ponnet heikosti violetit. Tähkälapakon alimpien nivelten reunanukka k e s k i p i t k ä ä. Tähkä melkein tasapaksu. Jyvät värittyvät fenolikäsittelyssä r u skeiks i (usein vähän kirjaviksi) ja kaleet vaaleamman ruskeiksi kuin

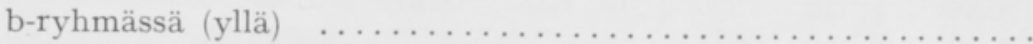

AURORE

\section{aa) Kaleet vaaleat, kaljut}

b) Lehden korvakkeiden reunoissa o n karvoja.

c) Tähkälapakon alimpien nivelten reunassa pit kä ä - k e s k ip i t k ä ä nukkaa.

d) Korren ylimmässä solmussa ja korressa solmun yläpuolella nukkaa vähän tai jonkin verran.

e) Jyvät värittyvät fenolikäsittelyssä v a a l e a n r u s k ei k s i. Lehden korvakkeissa antosyania, mutta yleensä vain reunoilla (näkyy parhaiten juuri ennen tähkimistä). Korren ylimmässä solmussa nukkaa jonkin verran. Tähkä tasapaksu, lapakon alimpien nivelten reunoissa k e s k i p i t k ä ä nukkaa (vrt. Kärniä). Jyvä suuri, suhteellisen lyhyt, vähän kärkeen kapeneva, kärjen nukkapinta vinossa

Lehdet melko pystyt ja kapeat, myöhään sinivihreät. Korressa yleensä runsaasti härmettä. Jyvä vähän lyhyempi ja paksumpi kuin Timantin jyvä, alkio tavallisesti hyvin sileä, jyvän kärkinukka yleensä pitempää kuin esim. Timantilla ............

$\left.{ }^{1}\right)$ Ks. Maataloustiet, aikak. 13 (1941): 163. 
ee) Jyvät värittyvät fenolikäsittelyssä tumman tai vaalean r u s k e a n kir j a vi ks i.

Lehdet melko nuokkuvat ja leveät, usein kellanvihreät. Korsi heikko, usein punertava. Tähkä melko paksu, kärkeen suippeneva; osalla violettipontiset heteet. Jyvä tavallisesti kärkeen päin kapeneva, melkein kuten Sopuvehnän jyvä, mutta selkäpuolelta loivempi ja kärjessä oleva nukkapinta enemmän vinossa . . . . .

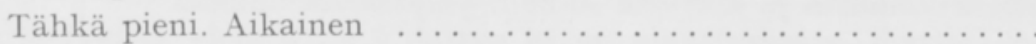

KIURU

GARNET

eee) Jyvät värittyvät fenolikäsittelyssä t u m m a n r u s k e i ks i.

Korsi melko pitkä, sen ylimmän solmun nukkaisuus vaihtelee, mutta yleensä nukkaa on vähän. Heteen ponnet vaalean keltaiset. Tähkä pitkä, harvahko, yleensä jo ennen tuleentumista vähän nuokkuva, kaareva. Kale kapeahko. Jyvä tavallisesti kärkeen päin kapeneva ja hiukan kulmikas ................ Lehdet kapeahkot. Korren solmujen nukkaisuus vaihtelee kuten Sovulla. Heteen ponnet heikosti violetit. Kale melko leveä, vähän ruskehtavampi kuin Sovulla. Tähkä jää usein kapeaksi. Jyvä pieni, lyhyt, pyöreäpäinen, ei aivan litteä, usein tummalaik-

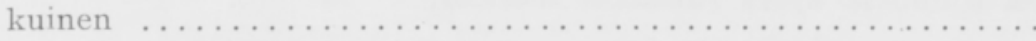

dd) Korren ylimmässä solmussa ja useimmilla lajikkeilla myös korressa solmun yläpuolella runsaasti nukkaa.

e) Jyvät värittyvät fenolikäsittelyssä va a l e a n r u s k e i k s i. Korsi melko lyhyt, sen solmuissa tavallisesti runsaasti nukkaa, mutta itse korressa solmun yläpuolella vain vähän nukkaa. Tähkä paksu ja lyhyt (joukossa usein joitakin ruskeakaleisia, mutta muten Tammen tyyppisiä tähkiä). Jyvä lyhempi ja paksumpi kuin Timantin jyvä, yleensä tasapaksu, joskus kärkeen päin kapeneva, alkio melko suuri $\ldots \ldots \ldots \ldots \ldots \ldots \ldots \ldots \ldots \ldots \ldots \ldots \ldots \ldots \ldots \ldots$ Lehdet leveät, varsinkin orasasteella usein nuokkuvat. Korsi pitempi kuin Tammella. Korressa solmun yläpuolella niin runsaasti nukkaa, että se tuntuu kosketettaessa karhealta. Tähkä melko suuri, kärjestä suippeneva, lapakon nivelet melko pitkät, kale leveä. Jyvä keilamaisesti kärkeen päin kapeneva, kärjen nukkapinta vinossa $\ldots \ldots \ldots \ldots \ldots \ldots \ldots \ldots \ldots \ldots \ldots \ldots \ldots \ldots \ldots \ldots \ldots \ldots$ Tähkä suuri, harvahko, Iapakon reunanukka pitkää. Jyvä tasapaksu, korkeampi kuin esim. Timantilla, kärkinukka melko

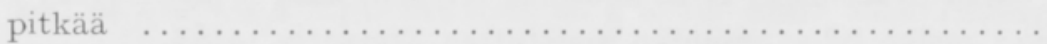

ee) Jyvät värittyvät fenolikäsittelyssä t u m m a n r u s k e i k s i.

Lehdet leveät, korsi pitkä. Sekä korren solmu että korsi solmun yläpuolelta kovin nukkaiset. Tähkä melko suuri, vähän kärkeen suippeneva; lapakon alin nivel kovin lyhyt. Kaleet leveät. Jyvä suuri, paksu, usein jauhomainen; kärjen nukkapinta vinossa, nukka melko pitkää . . . . . . . . . . . . . . . . Kuten edellinen, mutta korren solmussa ja solmun yläpuolella vähemmän nukkaa $\ldots \ldots \ldots \ldots \ldots \ldots \ldots \ldots \ldots \ldots \ldots \ldots \ldots \ldots \ldots \ldots \ldots \ldots \ldots$

Lehdet melko kapeat. Korressa ylimmän solmun yläpuolella hyvin runsaasti nukkaa. Tähkä melko paksu, mutta kärkeen suippeneva, lapakon nivelet pitkänlaiset, niiden reunanukan pituus vaihtelee pitkästä lyhyeen. Jyvä melkein kuten »Kanadalaisen», mutta ei niin paksu ja kärkinukka on lyhempää; jyvän pitkittäinen selkä-

\section{SOPU}

KIMMO

TAMMI

TER ̈̈

DROTT

"KANADALAINEN"

MARQUIS =

"TASKU" 
viiru on usein selvä. Fenolikäsittelyssä ovat jyvät 5 t:n kuluttua tavallisesti tumman ruskeat, mutta 24 t:n kuluttua vaaleammat

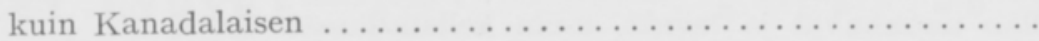

PRONSSI

(BRONS)

cc) Tähkälapakon alimpien nivelten reunanukka 1 y h y t ä tai ovat nivelet $\mathrm{k}$ a $1 \mathrm{j}$ u $\mathrm{t}$.

d) Korren ylimmässä solmussa ja korressa solmun yläpuolella nukkaa yleensä vähän tai ei yhtään.

e) Jyvät värittyvät fenolikäsittelyssä v a a l e a n r u s k e i k s i.

Oraan lehtitupet kaljumpia kuin kevätvehnillä yleensä. Lehden korvakkeissa kauttaaltaan antosyania (vertaa Svennoa). Lehdet melko myöhään sinivihreät. Tähkä suuri, tasapaksu; tähkälapakon nivelet lyhyet ja leveät. Jyvä suuri, leveä, suhteellisen lyhyt, yleensä vähän kärkeenpäin kapeneva, kärjen nukkapinta vähän vinossa, nukka kovin lyhyttä $\ldots \ldots \ldots \ldots \ldots \ldots \ldots \ldots \ldots \ldots \ldots \ldots \ldots \ldots \ldots \ldots \ldots$

KÄRNI

(KÄRN II)

dd) Korren ylimmässä solmussa hyvin runsaasti nukkaa.

e) Jyvät värittyvät fenolikäsittelyssä v a a l e a n r u s k e i k s i.

Lehdet myöhään sinivihreät; lehden reunoissa usein karvoja. Korressa solmun yläpuolella nukkaa vain kohtalaisesti. Tähkä melko suuri, tasapaksu, lapakon nivelet pitkähköt (reunanukan pituus vaihtelee). Jyvä kärkeen päin kapeneva ........... Lehdet myöhään sinivihreät (vielä myöhäisempi kuin Pondus), pystyt. Korressa solmun yläpuolella runsaasti nukkaa. Tähkä melko suuri, kärkeen suippeneva $\ldots \ldots \ldots \ldots \ldots \ldots \ldots \ldots \ldots$

PONDUS

EXTRA-

KOLBEN II

bb) Lehden korvakkeista noin puolet il man re u n a k r voja.

c) Tähkälapakon alimpien nivelten reunanukka p i t k ä ä - k e s k i$\mathrm{p}$ i t k ä ä.

d) Korren ylimmässä solmussa nukkaa vähän tai jonkin verran (korressa solmun yläpuolella vähemmän kuin solmussa).

e) Jyvät värittyvät fenolikäsittelyssä va a le a n r u s k e i k s i.

Lehdet ja tähkä pystymmät ja korsi vähän lyhempi kuin Sopuvehnän. Jyvä melko lyhyt, muuten muistuttaa Timantin jyvää

\section{VIHNEET PITK ̈ T}

\section{a) Kaleet ruskeat, kaljut}

b) Lehden korvakkeiden reunoissa e i karvoja.

Tähkälapakon alimpien nivelten reunanukka keskipitkää - lyhyttä. Jyvät melko pitkiä ja kapeita, värittyvät fenolikäsittelyssä ruskeiksi, vähän kirjaviksi $\ldots \ldots \ldots \ldots \ldots \ldots \ldots \ldots \ldots \ldots \ldots \ldots \ldots \ldots \ldots \ldots \ldots \ldots \ldots$

Jyvät suurempia, paksumpia ja värittyvät fenolikäsittelyssä tasaisemmin tumman ruskeiksi kuin Hankkijan Ruskean jyvät. (Alkujaan sveitsiläinen, viljellään nykyään mm. Kotkan ympäristössä)

HANKKIJAN

RUSKEA

"VIHNEVEHNÄ" 


\section{aa) Kaleet vaaleat, kaljut}

b) Lehden korvakkeiden reunoissa o n karvat. Tähkälapakon alimpien nivelten reunanukka $\mathrm{p}$ it $\mathrm{k}$ ä ä.

Korren ylimmän solmun nukkaisuus vaihtelee, mutta yleensä nukkaa on hyvin vähän. Jyvä yleensä melko pitkä, a $1 \mathrm{k}$ i o s u u ri, kurttuinen. Jyvät värittyvät fenolikäsittelyssä yleensä kirjaviksi, (kärkipää tummemman ruskea kuin alkiopää) tai on osa jyvistä vielä 5 t:n kuluttua aivan muttumatta, mutta osa kokonaan ruskeita tai kirjavia $\ldots \ldots \ldots \ldots \ldots \ldots \ldots \ldots \ldots \ldots \ldots \ldots \ldots \ldots$ Muistuttaa suuresti edellistä, mutta kaleet ovat vähän kapeammat ja pitemmät, samoin jyvät, jotka sitäpaitsi värittyvät fenolikäsittelyssä tumman ruskeiksi $\ldots \ldots \ldots \ldots \ldots \ldots \ldots \ldots \ldots \ldots \ldots \ldots \ldots \ldots$

APU

PIKA II

bb) Lehden korvakkeista noin puolet ilman reunakarvo j a.

Kuten Pika II, mutta $\mathrm{k}$ a l e et värittyvät fenolikäsittelyssä vaalean ruskeiksi, Pika II:n taas tumman ruskeiksi (molempien

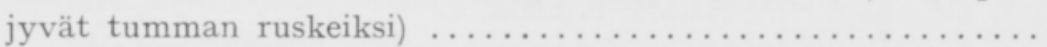

PIKA I

SUMMARY:

ON SOME CHARACTERISTICS OF SPRING WHEAT VARIETIES

ELLI KORPINEN

State Seed Testing Station, Helsinki

The sale of seed for sowing purposes is not allowed in Finland without a guarantee based on a certificate issued by the State Seed Testing Station. The guarantee, however, covers only germination and purity, but it is commonly issued, particularly with all cereals, to cover also genuinneness of variety, though it is compulsory only with regard to the two top quality seed classes and does not concern ordinary seed on sale. The State Seed Testing Station must therefore possess a thorough knowledge of the varieties and their differentiation. Characteristics of the varieties are subject to constant study with new varieties appearing on sale. The above table of investigation on spring wheat varieties is a result of these studies and contains all the varieties that have been on sale at least for some time during the past 20 years, and of which a sample has been sent to the State Seed Testing Station in accordance with the seed law. Altogether 25 varieties of spring wheat are presented here.

The newest, as well as some of the oldest varieties, have been studied only some $2-3$ years, most varieties, however, for $10-20$ years. Characteristics of the varieties have been investigated both in the laboratory and in the field.

The above table of investigation provides a supplement to the table published earlier in this journal (Journal of the Scientific Agricultural Society of Finland, Vol. 13, 1941 (145-164)). In each the spring wheat varieties are classified approximately according to the same characteristics. 